In referring to a "rebound" in serum-cholesterol level on resumption of normal diet by experimental subjects, your article conveys a disturbing misinterpretation of our observations. As indicated in fig. 20 of our report, we tested this question by selecting the 10 experimental subjects and the 11 control subjects who had had the best and most prolonged adherence. During the 8 months before termination of the experimental diet, these two subgroups had nearly identical mean serum-cholesterol concentrations. This must be attributed to chance, since the larger groups from which the sub-samples were drawn displayed lower mean levels among the experimental subjects than among the controls (see fig. 5 of our report). On resumption of the regular diet, the experimental subgroup displayed a prompt serum-cholesterol rise comparable in magnitude to the fall seen at the start of the study. Their levels were now higher than those of the control subgroup. This was surely not a "rebound" phenomenon, but rather an expression of the fact that non-dietary influences had set serum-cholesterol levels higher in these 10 experimental subjects than in the 11 men with whom they were compared.

$$
\text { Wadsworth Veterans }
$$

Administration Hospital and

U.C.L.A. School of Medicine,

Los Angeles, California.

\section{SEYMOUR DAYTON}

Morton Lee Pearce.

\section{POLYUNSATURATED FATTY ACIDS AND MYOCARDLAL INFARCTION}

SIR,-Dr. Kingsbury and his colleagues (Dec. 20, p. 1325) make the following statement in their paper on polyunsaturated fatty acids and myocardial infarction: "Epstein also found no relationship between plasma-cholesterol or blood-sugar and new ischæmic events in patients with myocardial infarction over a similar three to four-year period ". I am afraid that this is a misquotation from the presentation to the Royal Society of Medicine." Our data from the Tecumseh Community Health Study did not refer to such " new ischæmic events" but to new events among persons initially free of manifest disease. This, I hope, was quite apparent from the text. Moreover, it is incorrect to say that we did not find a relationship between plasma-cholesterol (or, rather, serum-cholesterol) and blood-sugar, as stated by Dr. Kingsbury and his associates. The actual findings, and some of their seeming inconsistencies, are carefully discussed in the original paper, and I do not want to impose on your space to recapitulate them. I will merely say that the numbers in the oldest and youngest age-groups amongst men were small, and so was the number of women who developed clinical events. Furthermore, the new clinical events identified in detail in my paper, ${ }^{1}$ included angina pectoris and certain electrocardiographic ST-T wave changes which are less definite "endpoints" than heart attacks. Even so, coronary heartdisease and serum-cholesterol levels are, indeed, associated amongst men in the important 40-59 age-group. With regard to blood-sugar, the preliminary data in my paper to the effect that persons with high blood-sugar are preferentially prone to death has now been further substantiated. ${ }^{2}$

Surely, there is no reasonable doubt about the association between coronary heart-disease and serum-cholesterol. ${ }^{3}$ Similarly, it seems to be more and more likely that hyperglycemia is also a predisposing factor towards coronary disease. ${ }^{4,5}$ It is only to be expected that there will be, from

1. Epstein, F. H. Proc. R. Soc. Med. 1967, 60, 56

2. Ostrander, L. D., Jr. Hyperglycemia and vascular disease in Tecumseh, Michigan. Proceedings of the First International Symposium on Early Diabetes, Marbella, Spain, Oct. 23-26, 1968. New York (in the press).

3. Epstein, F. H. F. Am. med. Ass. 1967, 201, 795.

4. Epstein, F. H. Circulation, 1967, 36, 609.

5. Epstein, F. H. Minnesota Med. 1969, 52, 1271. time to time, reports which are exceptions to the general rule that elevated cholesterol, or, for that matter, bloodpressure or glucose levels, predispose to ischæmic heartdisease. Acheson and Florey ${ }^{6}$ have pointed out very well that a given predisposing factor is not necessarily operative in all ecological settings where multiple genetic and environmental influences interact. The urgent need is not so much to argue over these associations but to test, by means of preventive trials, whether they are causative.

To return to the paper by Dr. Kingsbury and his group, it is perhaps not surprising that they find no association between plasma-cholesterol and blood-sugar concentrations and the degree of arterial disease. After all, their subjects already had disease of such an advanced degree that they were patients attending the hospital with manifestations of peripheral atherosclerosis. Even though a biological factor may cause the gradual development of arterial disease, the extent of the disease in its late stages is not necessarily related to the level of this factor at this advanced stage. All this does not in the least detract from this and earlier work by Dr. Kingsbury on the possible importance of polyunsaturated fatty acids in the genesis of atherosclerosis.

School of Public Health,

University of Michigan, Ann Arbor, Michigan 48104.

FREDERICK H. EPSTEIN.

\section{HEREDITARY HEMORRHAGIC TELANGIECTASIA: AGGRAVATION BY ORAL CONTRACEPTIVES?}

SIR,-We have seen three women with hereditary hæmorrhagic telangiectasia (H.H.T.) whose disease may have been aggravated by oral ostrogens.

A 46-year-old woman of Spanish descent, admitted for an unrelated cause, had had epistaxes since childhood, anæmia of undetermined cause since age 15, and facial telangiectasias and intermittent melæna since age 31 . Her paternal grandfather had bled to death from a nosebleed; her father and two sons had typical cutaneous telangiectasias. $2^{1 / 2}$ years ago she began oral contraceptives; six months later her facial lesions began enlarging, one becoming quite disfiguring; and one year ago epistaxes recommenced.

A review of hospital records of patients with H.H.T. revealed only one other who had been on oral contraceptives. This woman of 31 had telangiectasias of the skin and mucous membranes, and her mother had a history of epistaxes. The patient's epistaxes began 5 years ago, while she was taking 'Estinyl' (ethinylostradiol) for regulation of menstruation. They became worse during each of 3 pregnancies, and during the last, cautery was necessary 38 times. Despite a submucous resection, epistaxes continue to limit her activity.

Subsequently we saw a 42-year-old Mexican-American woman, whose mother and son had had troublesome epistaxes. She had been taking an oral contraceptive 'Ovo' for 4 years. 2 years ago she noticed telangiectasias for the first time. Located on her finger tips and tongue, they have since grown larger, and frequently bleed on minor trauma. In the past year she has had occult gastrointestinal bleeding and anæmia.

The records of six other nearby hospitals (over 500,000 admissions) were searched for other instances of women with H.H.T. who were on oral contraceptives. None was found. Recently, however, one of us examined a MexicanAmerican woman with H.H.T. at Denver General Hospital before and repeatedly during the first 10 months of oral contraceptive therapy. Her lesions neither enlarged nor 6. Acheson, R. M., Florey, C. du V. Lancet, 1969, ii, 391. 